\title{
Bio-stimulation by seed priming with Bacillus subtilis for suppressing seed-borne fungal pathogens of vegetables in Bangladesh
}

\author{
F. H. Tumpa, A. Sultana, M. Z. Alam and M. A. R. Khokon* \\ Laboratory of Biosignaling and Bioactive Compounds, Department of Plant Pathology, Bangladesh Agricultural \\ University, Mymensingh-2202, Bangladesh, *E-mail: atiq.ppath@bau.edu.bd
}

\begin{abstract}
Aqueous formulation of rhizopheric beneficial bacteria viz. Bacillus subtilis, an exotic strain collected from Russia was assayed for its performance to suppress the growth of various seed-borne fungi of vegetable. The performance of the bio-agent was appraised based on growth suppression by dual culture method and reduction of seed-borne fungi in the bio-agent treated seeds. Ten seed samples comprise of summer and winter vegetables were examined collected from different local farmers. A total of fourteen fungal species belongs to twelve genera viz. Fusarium moniliforme, Botrytis cinerea, Aspergillus flavus, F. oxysporum, Botryodiplodia theobromae, Macrophomina phaseolina, A.niger, Cercospora sp., Phoma exigua, Rhizopus sp., Colletotrichum sp., Phytophthora sp., Penicillium sp., and Curvularia sp. were recorded from different untreated seeds. Vegetables seeds were treated in a concentration $\left(10^{-3}\right)$ of aqueous formulation of $B$. subtilis for two hours followed by air drying for 30 minutes. In general, the incidences of all fungal species of all kinds of vegetables seeds were reduced. But, selectively the best performances were observed in tomato, brinjal, cucumber, wax gourd and okra where most of the fungal species were completely suppressed by seed treatment with Bacillus subtilis. The growth of seed-borne fungi was inhibited highest in wax gourd (100\%). The growth inhibition was also at satisfactory level in cucumber (95\%), tomato (95\%), brinjal (92\%) and okra (86\%) seeds. The findings of this research indicate the possibility of utilizing $B$. subtilis as seed treating agents instead of chemical fungicides to control seed-borne diseases of vegetables.
\end{abstract}

Keywords: Bacillus subtilis, Seed priming, Seed-borne fungi, Vegetable

\section{Introduction}

Eco-friendly sustainable disease management strategies are the prime concern for crop producers across the world where bio-agents collected from the natural ecosystem play a pivotal role. Stimulation of plants innate immunity by exploiting natural bio-agents has been utilized in many plant diseases. Induced systemic resistance activated by microbial components can resist a wide range of pathogens (Alizadeh et al. 2013). Bacillus subtilis produces a wide range of bioactive molecules among which lipopeptides; surfactin, iturin and fengycin families. In a recent study it is reported that surfactin, a bioactive compound derived from Bacillus subtilis showed elicitation of systemic resistance (ISR) in tomato against tomato mosaic virus (Hussein et al. 2016 and Devendra et al. 2009). Plant protection from various disease resulting from ISR elicited by Bacillus spp. (Van Loon, 2007). has been reported against leaf-spotting fungal and bacterial pathogens, systemic viruses, a crown-rotting fungal pathogen, root-knot nematodes, and a stem-blight fungal pathogen as well as damping-off, blue mold, and late blight diseases (Turner and Backman, 1991 and Abo-Elnaga, 2006). Bio-priming is a new technique of seed treatment that integrate biological and physiological aspects of disease control has recently been used as alternative method for controlling many seeds and soil borne pathogens (Ferreira et al., 1991; El-Mohamedy, 2008). Coating seeds of vegetables with bio-control agent such as Bacillus subtilis is the most effective treatment for controlling many seed-borne pathogens. Seed priming with $B$. subtilis have since been shown to control various diseases in vegetables. The inhibitory effect of Bacillus subtilis on plant pathogenic fungi has been frequently reported in laboratory, greenhouse, and field studies. $B$. subtilis is able to synthesize more than 60 different types of antibiotics, mainly in polypeptides, many of which possess antifungal effects. B. subtilis produces antibiotics, including some called iturins, which help the bacteria compete with other microorganisms either by killing them or reducing their growth rate (Singh et al., 2016). When applied directly to seeds, $B$. subtilis colonizes the developing root system, competing with various disease organisms that attack root systems. According to the manufacturers, $B$. subtilis also inhibits plant pathogen spore germination and interferes with the attachment of the pathogen to the plant. When soil or seed-applied, it is claimed that $B$. subtilis feeds off plant root exudates, depriving pathogens of a food source. 
Keeping these views in mind, the present investigation was designed to assay the potential of $B$. subtilis for seed priming for reducing the incidence of seed-borne fungi of several vegetable crops which can eventually improve the quality seedlings as well as increase the yield of crops and reduce indiscriminate use of chemical pesticides.

\section{Materials and Methods}

Seeds of ten vegetable crops (Bottle gourd, Sweet gourd, Snake gourd, Wax gourd, Cucumber, Tomato, Brinjal, Raddish, Bean and Okra) were collected from the farmers of Mymensingh district. These seeds were stored in zip-lock bags in refrigerator for further studies. In order to investigate the viability of the formulated product of Bacillus subtilis, colony forming unit (cfu) was observed and counted on Nutrient Agar (NA) medium. One $\mathrm{mL}$ of suspension from each dilution series was poured on NA medium and wiped with a sterile glass rod. The next day, colony forming unit (whitish colony of bacterium) was formed and their number was counted. To detect the seed-borne fungi Blotter method was followed according to ISTA rules for seed testing (ISTA, 2001). Three layers of blotting papers (Whatman no. 1) were soaked in sterilized water and placed at the bottom of $9 \mathrm{~cm}$ diameter plastic petridish and over which the seeds were plated. Four hundred seeds were examined per sample. The seeds were incubated in the incubation chamber at $20 \pm 2^{\circ} \mathrm{C}$ under alternating cycles of 12 hours near ultraviolet (NUV) light and darkness for 7 days. Additional water was supplemented to moisten the blotter paper when necessary. In order to prepare and select the dilution series from stock solution of Bacillus subtilis $10^{-1}, 10^{-2}, 10^{-3}, 10^{-4}$, $10^{-5}$ and $10^{-6}$ times dilution solutions were prepared with distilled water. Before, conducting any experiment the viability of the imported formulation was examined by making the series dilution and subsequent plating on Nutrient Agar (NA) medium and incubated them at room temperature for 2-3 days. Colony developed on NA medium were examined visually and counted. Seed priming was accomplished by dipping the vegetables seeds in $10^{-3}$ dilution of stock solution of $B$. subtilis for $2 \mathrm{hrs}$ at room condition $\left(\begin{array}{ll}25 \pm 2 & C\end{array}\right)$. Afterwards, the solution was drained out and the seeds were allowed to dry. Then, the seeds were placed in blotting paper according to the ISTA rules for seed health testing (ISTA, 2001). Each individual incubated seed was observed under stereomicroscope at 16x and 25x magnifications in order to record the incidence of seed-borne fungi. Most of the associated fungi were detected by observing their growth characters on the incubated seeds on blotter paper. The fungal associations were presented as percent incidence for individual fungi.

\section{Results and Discussion}

\section{Effect of seed treatment by Bacillus subtilis on the association of seed-borne fungi in summer vegetable seeds}

A total of five summer vegetables viz. sweet gourd, wax gourd, snake gourd, cucumber and okra were considered for investigating the association of seed-borne fungi collected from the farmers. The most fungi belong to the genera Fusarium, Macrophomina, Colletotrichum, Aspergillus, Curvularia, Botrytis, Rhizopus, Phoma were predominantly associated at various intensity with most of the seed samples (Fig. 1-5). In sweet gourd, the highest (44\%) prevalence was recorded in case of Aspergillus niger followed by Rhizopus sp. (35\%), Fusarium oxysporum (34\%), F. moniliforme (28\%). The prevalence of $M$. phaseolina, Colletotrichum sp., A. niger was completely suppressed by seed priming by Bacillus subtilis suspension (Fig. 1). 


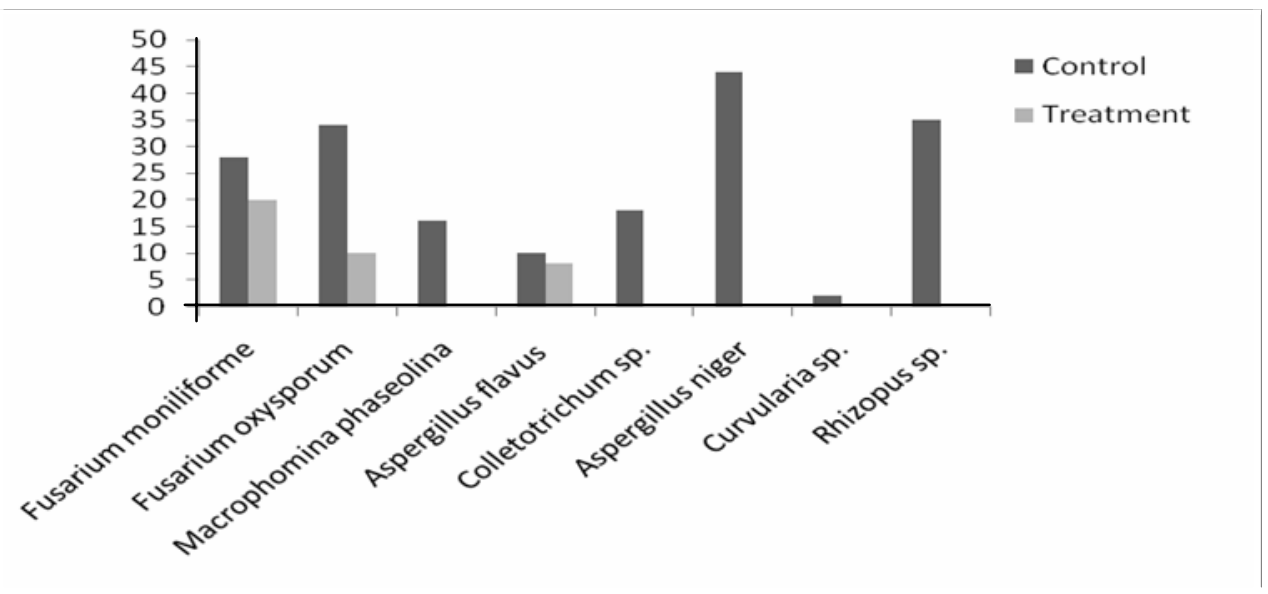

Fig. 1. Effect of Bacillus subtilis on percent prevalence of seed-borne fungi in Sweet gourd (Cucurbita moschata)

The higher prevalence of $A$. niger (54\%), Rhizopus sp. (52\%), M. phaseolina (40\%) and Phoma exigua $(38 \%)$ was recorded in wax gourd seeds. Priming of seed completely suppressed the growth of all fungi (Fig. 2).

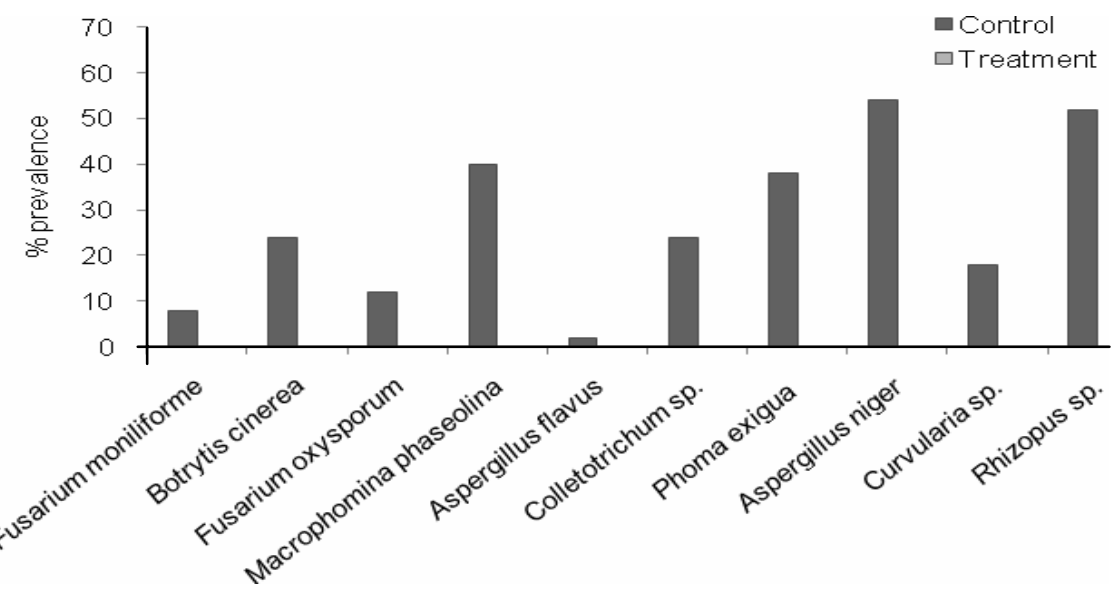

Fig. 2. Effect of Bacillus subtilis on percent prevalence of seed-borne fungi in Wax gourd (Benincasa hispida)

Severe seed-borne fungal infection was observed in snake gourd seeds (Fig. 3). The most prevalent fungi were B. cinerea (82\%), F. moniliforme (76\%), A. flavus (68\%) and F. oxysporum (42\%). Seed treatment by $B$. subtilis suppressed the fungal growth in case of $B$. cinerea $(50 \%), F$. moniliforme $(40 \%), A$. flavus (30\%), F. oxysporum (20\%), while complete suppression was also recorded in case of M. phaseolina, $A$. niger and Rhizopus sp. and Penicillium sp.

The prevalence of seed-borne fungi in cucumber was recorded higher in case of $F$. oxysporum (56\%), $A$. flavus (54\%), F. moniliforme (46\%) and B. cinerea (40\%) (Fig. 4). A satisfactory level of suppression of seed-borne fungi by $B$. subtilis was observed in cucumber seeds where the association of $F$. moniliforme, B. cinerea, M. phaseolina, A. flavus, Colletotrichum sp., Cercospora sp., Penicillium sp., and $P$. exigua was completely suppressed as well as least association was also recorded in case of $F$. oxysporum $(10 \%)$. 


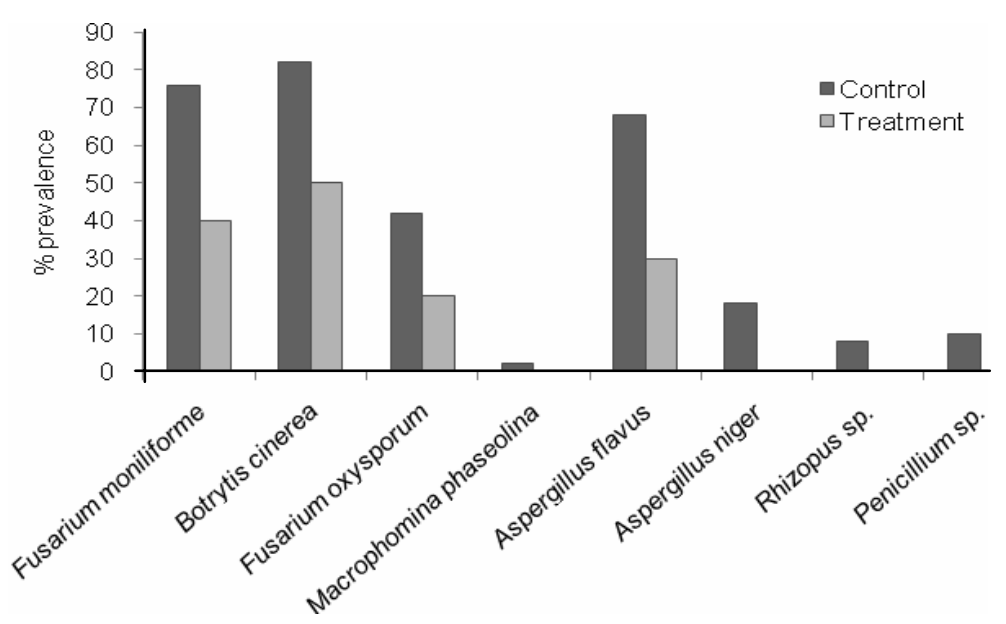

Fig. 3. Effect of Bacillus subtilis on percent prevalence of seed-borne fungi in Snake gourd (Trichosanthes cucumerina)

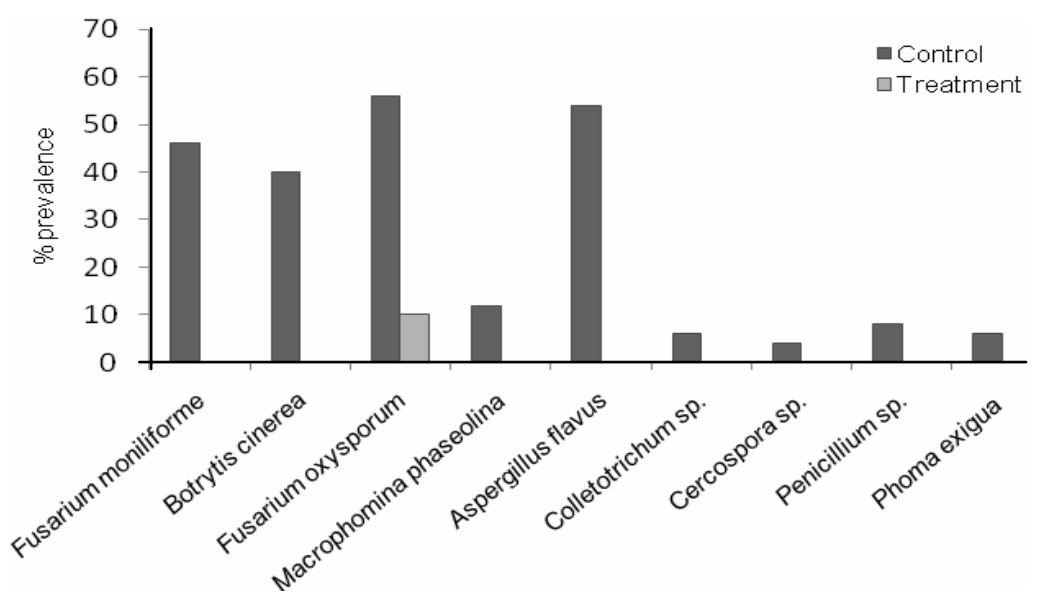

Fig. 4. Effect of Bacillus subtilis on percent prevalence of seed-borne fungi in Cucumber (Cucumis sativus)

Association of seed-borne fungi at different frequency was recorded in okra seeds such as $B$. cinerea (96\%), F. moniliforme (64\%), A. flavus (60\%), Rhizopus sp. (60\%), F. oxysporum (54\%) and $M$. phaseolina (52\%). The growth of all fungi except Aspergillus sp. was completely suppressed by seed treatment by $B$. subtilis (Fig. 5).

Among all the seed-borne fungi of summer vegetables, seed treatment by $B$. subtilis showed the strong suppression ability, the best suppression ability was observed in case of okra and cucumber seeds where almost $100 \%$ suppression of seed-borne fungi was recorded.

\section{Effect of seed treatment by Bacillus subtilis on the association of seed-borne fungi in winter vegetable seeds}

A total of five winter vegetables viz. bottle gourd, bean, raddish, tomato and brinjal were considered for investigating the association of seed-borne fungi collected from the farmers. The most fungi belong to the genera Fusarium, Macrophomina, Colletotrichum, Aspergillus, Curvularia, Botrytis, Rhizopus, Phoma, Phytophthora, Penicillium, Cercospora were predominantly associated at various intensity with most of the seed samples (Fig. 6-10). In bottle gourd the highest (66\%) prevalence was recorded in case of Botrytis cinerea followed by Fusarium oxysporum (24\%), F. moniliforme (18\%). The prevalence of $M$. phaseolina, Cercospora sp., Phoma exigua, and A. niger was completely suppressed by seed treatment by Bacillus subtilis suspension (Fig. 6). 


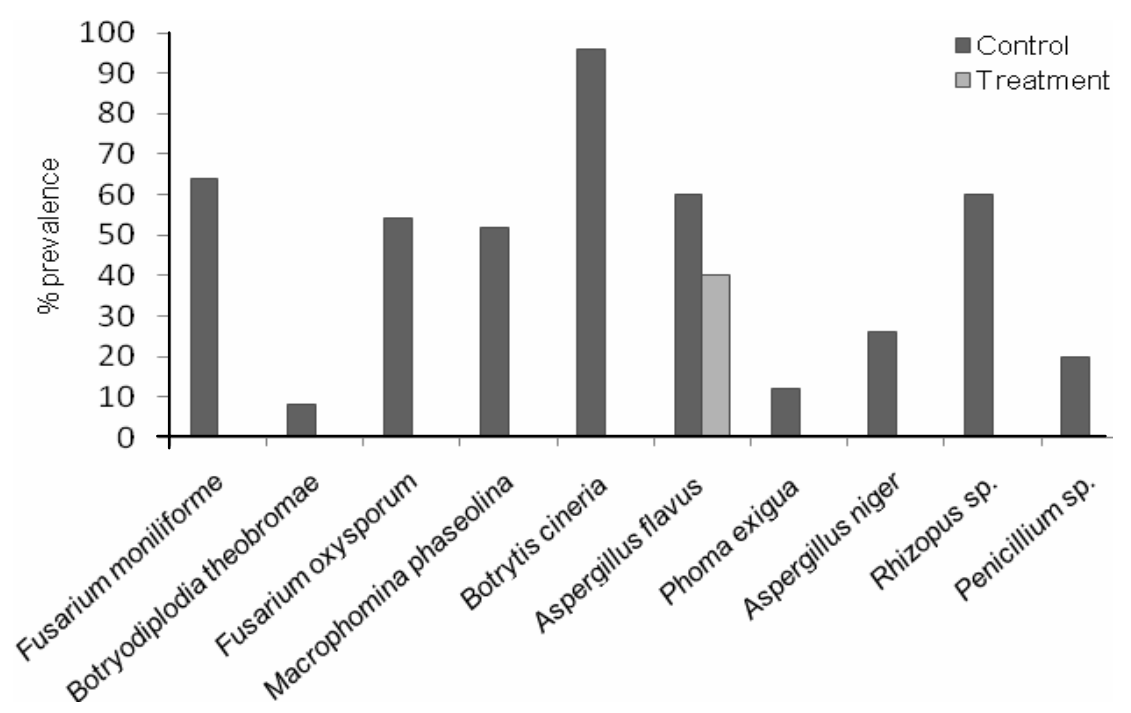

Fig. 5. Effect of Bacillus subtilis on percent prevalence of seed-borne fungi in Okra (Abelmoschus esculentus)

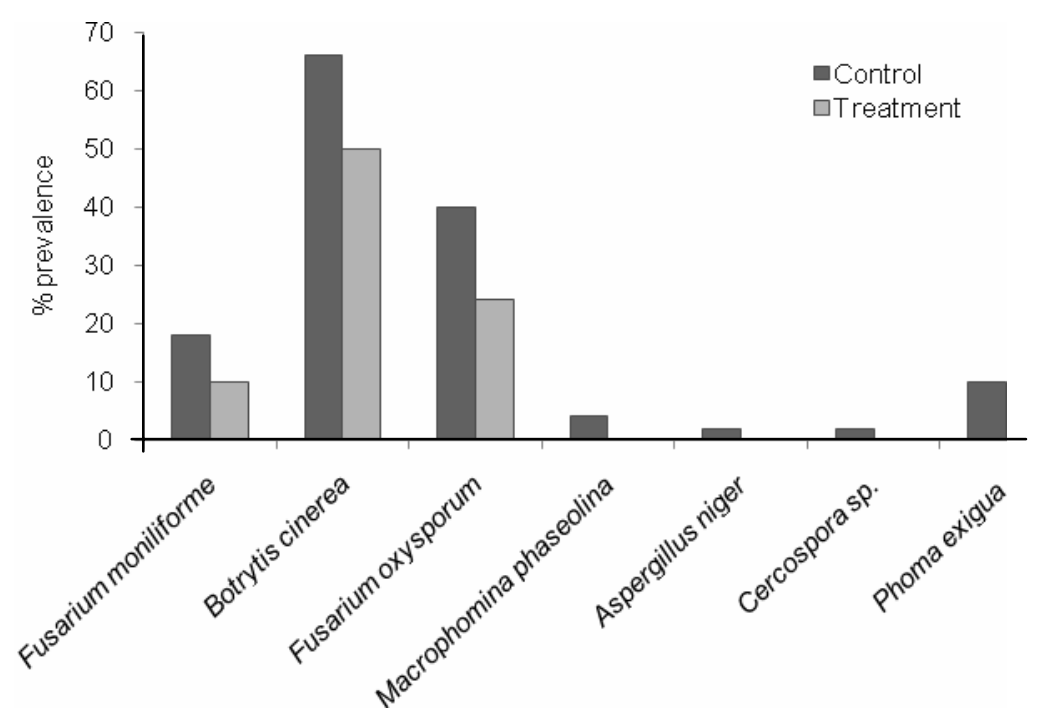

Fig. 6. Effect of Bacillus subtilis on percent prevalence of seed-borne fungi in Bottle gourd (Lagenaria vulgaris)

The higher prevalence of Aspergillus flavus (80\%), Fusarium oxysporum (44\%), Botrytis cinerea (34\%), Curvularia spp. (44\%) and Aspergillus niger (28\%) in bean seeds. Seed treatment suppresses successfully the growth of $M$. phaseolina, B. cinerea, Colletotrichum sp., Rhizopus sp. and Curvularia sp. (Fig. 7).

Severe seed-borne fungal infection was observed in radish seeds (Fig. 8). The most prevalent fungi were Aspergillus niger (44\%), F. moniliforme (20\%), Macrophomina phaseolina (15.2\%) and F. oxysporum (13.2\%). Seed treatment by $B$. subtilis completely suppressed the fungal growth of Colletotrichum sp., Macrophomina phaseolina and Rhizopus sp. 


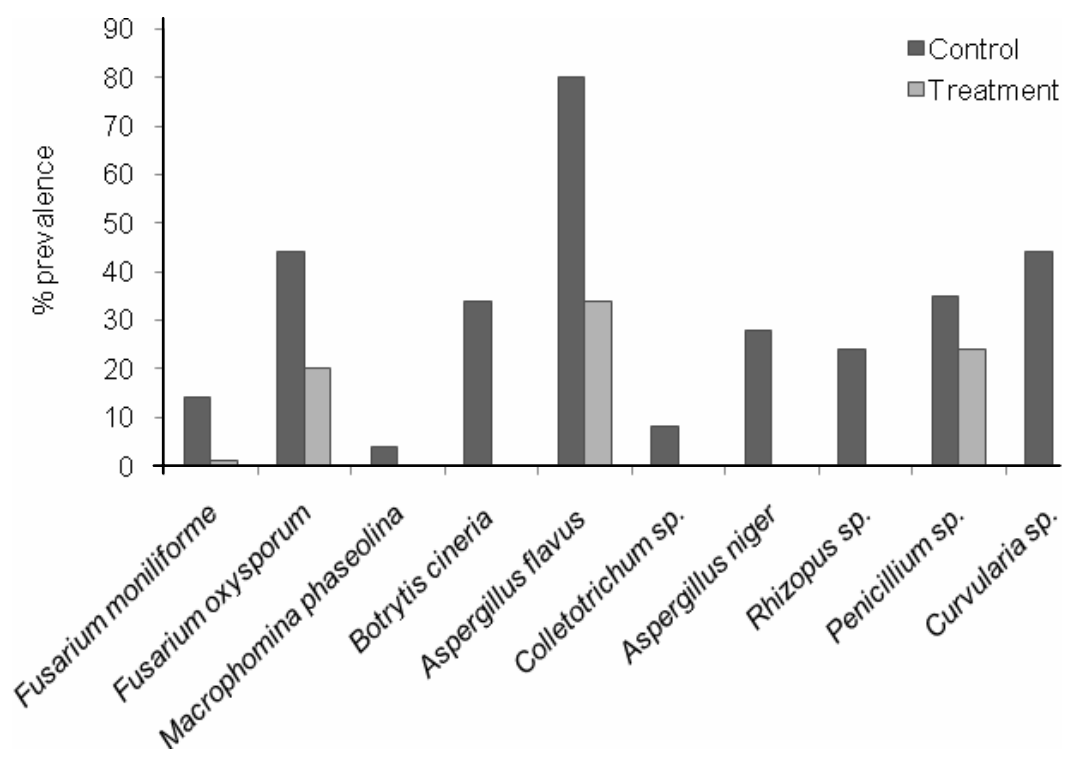

Fig. 7. Effect of Bacillus subtilis on percent prevalence of seed-borne fungi in Bean (Phaseolus vulgaris)

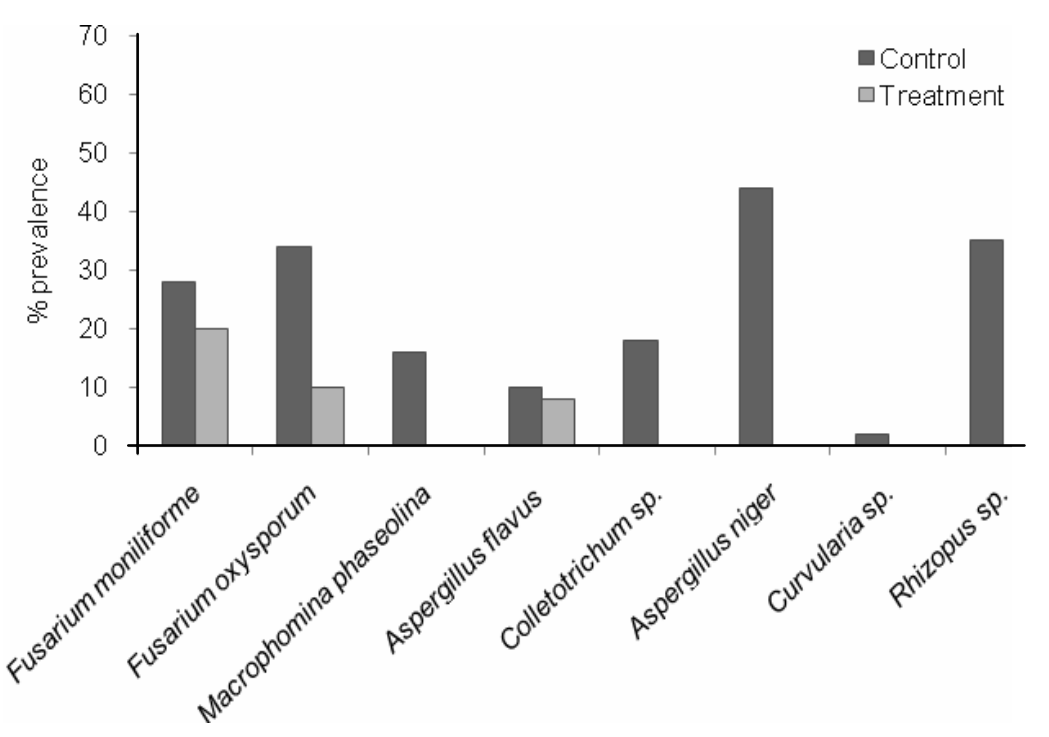

Fig. 8. Effect of Bacillus subtilis on percent prevalence of seed-borne fungi in Radish (Raphanus sativus)

The prevalence of seed-borne fungi in tomato was recorded higher in case of Phoma exigua (23.2\%), Rhizopus sp. (22.4\%), Macrophomina phaseolina (18.4\%) and Curvularia sp. (16\%) (Fig. 9). Complete suppression of seed-borne fungi by $B$. subtilis was observed in tomato seeds where the association of $B$. cinerea, F. oxysporum, Macrophomina phaseolina, A. niger, Cercospora sp., Rhizopus sp., Phytophthora $s p$., Colletotrichum $s p$. and Curvularia $s p$. was completely suppressed as well as least association was also recorded in case of $F$. moniliforme (1\%). 


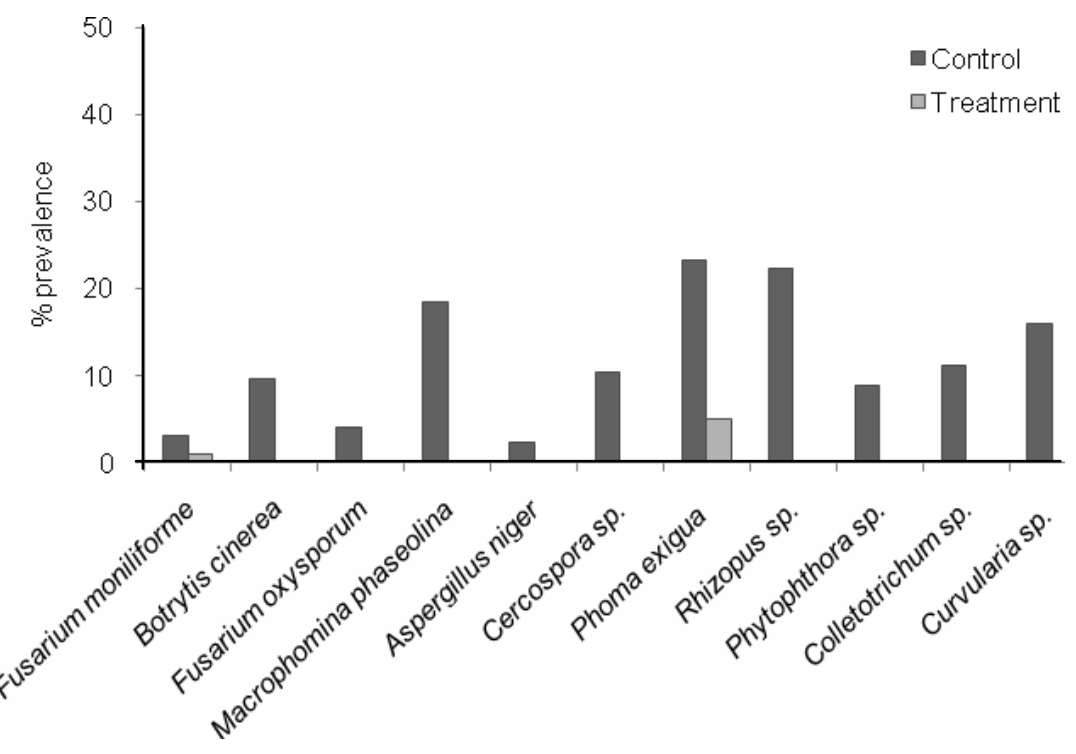

Fig. 9. Effect of Bacillus subtilis on percent prevalence of seed-borne fungi in Tomato (Solanum lycopersicum)

Association of seed-borne fungi at different frequency was recorded in brinjal seeds such as Aspergillus niger (32\%), F. moniliforme (14.4\%), A. flavus (14.4\%), Phoma exigua (9.6\%), F. oxysporum (8\%) and B. cinerea (7.2\%). The growth of fungi $F$. moniliforme, B. cinerea, Macrophomina phaseolina, A. niger, Phoma exigua, Penicillium sp., Phytophthora sp., Colletotrichum sp. and A. flavus were completely suppressed by seed treatment by $B$. subtilis (Fig. 10).

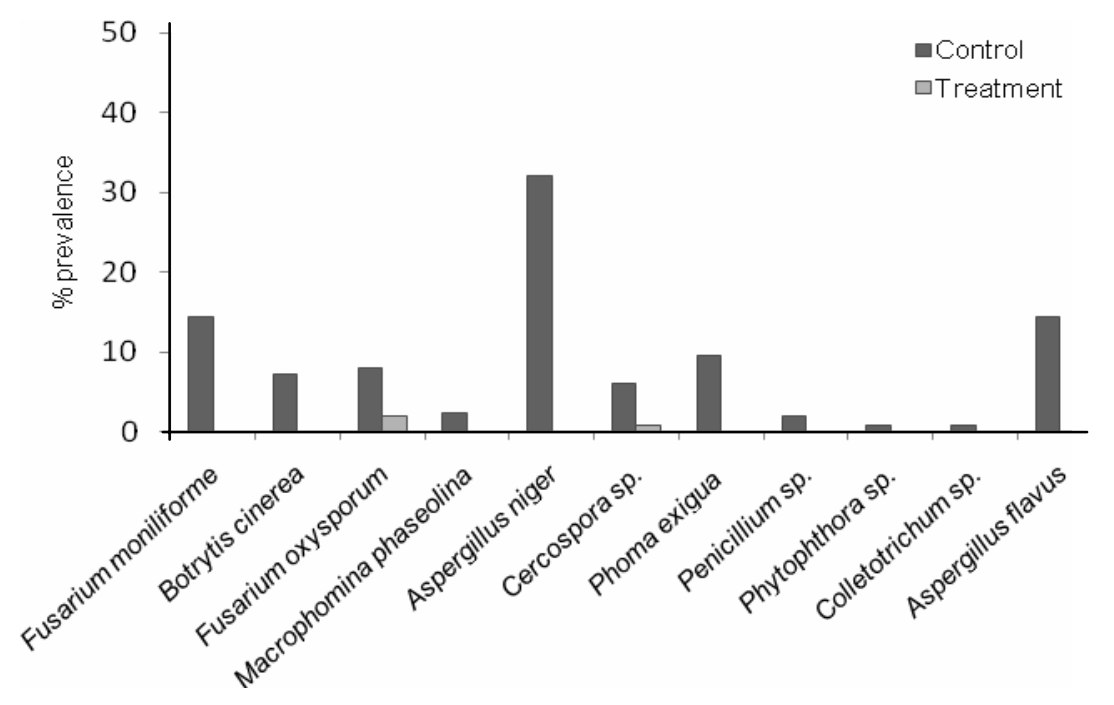

Fig. 10. Effect of Bacillus subtilis on percent prevalence of seed-borne fungi in Brinjal (Solanum melongena) 
Among all the seed-borne fungi of winter vegetables, seed treatment by $B$. subtilis showed the strong suppression ability, the best suppression ability was observed in case of radish seeds where almost $100 \%$ suppression of seed-borne fungi was recorded. A variation was found among the response by seed priming.

Therefore, it might be due to fact that elicitation of defense gene had a great variation in different kinds of vegetable seeds to show different kinds of suppression ability. The potentiality of $B$. subtilis has been articulated by many researchers in many aspects. Cubeta et al. (1985) conducted experiments on seed treatment with Bacillus subtilis to control fungal pathogen of soybean and they found fungistatic nature of $B$. subtilis against all isolated pathogens in in vitro condition. Ashwini and Srividya (2014) reported the potentiality of $B$. subtilis against anthracnose disease of chili caused by Colletotrichum capsici where the seeds treated with $B$. subtilis showed substantial reduction of fungal association compared to control. Podile and Prakash (1996) stated that groundnut seeds bacterized with $B$. subtilis showed a reduced incidence of crown rot in $A$. niger infested soil, suggesting a possible role of $B$. subtilis in biological control of $A$. niger. Our findings also reflect the potentiality of $B$. subtilis in controlling seed-borne fungi associated with different vegetables seeds.

\section{References}

Alizadeh, O., Azarpanah, A. and Ariana, L. 2013. Induction and modulation of resistance in crop plants against disease by bioagent fungi (arbuscular mycorrhiza) and hormonal elicitors and Plant Growth Promoting Bacteria. International Journal of Farming and Allied Sciences. 2322-4134.

Ashwini, N. and Srividyam S. 2014. Potentiality of Bacillus subtilis as biocontrol agent for management of anthracnose disease of chilli caused by Colletotrichum gloeosporioides OGC1.3 Biotech 4:127-136.

Cubeta, M.A., Hartman, G.L. and Sinclair, J.B. 1985. Interaction between Bacillus and fungi associated with soybean seeds. Plant Disease, 69 (6): 506-509.

Devendra, K., Choudhary Bhavdish, and Johri, N. 2009. Interactions of Bacillus spp. and plants - With special reference to induced systemic resistance (ISR). Microbiological Research. 164:493-513.

El-Mohamedy, R.1 S.R. and Abd El-Baky, M.M.H. 2008. Evaluation of Different Types of Seed Treatment on Control of Root Rot Disease, Improvement Growth and Yield Quality of Pea Plant in Nobaria Province. Research Journal of Agriculture and Biological Sciences, 4(6): 611-622.

Ferreira F.H. and Araujo A. 1991. Paleoparasitology and the Antiquity of Human Host-parasite Relationships. Mem Inst Oswaldo Cruz, Rio de Janeiro, 959(I): 89-93.

Heidi I. G. and Abo-Elnaga. 2006. Bacillus subtilis as a biocontrol agent for controlling sugar beet damping-off disease. Egypt. J. Phytopathol. 34(1):51-59.

Hussein, W., Awad, H. and Fahim, S. 2016. Systemic resistance induction of tomato plants against ToMV virus by surfactin produced from Bacillus subtilis BMG02. American Journal of Microbiological Research 4, (5): 153-158.

ISTA (International Seed Testing Association). 2001. International Rules for Seed Testi.

Podile, A.R. and Prakash, A.P. 1996. Lysis and biological control of Aspergillus niger by Bacillus subtilis AF 1. Canadian Journal of Microbiology 42(6):533-538.

Singh A., Gupta, R. and Pandey, R. 2016. Rice Seed Priming with Picomolar Rutin.

Enhances Rhizospheric Bacillus subtilis CIM Colonization and Plant Growth. PLOS ONE. 1-17.

Turner J.T. and Backman, P.A. 1991.Factors relating to peanut yield increases after seed treatment with Bacillus subtilis. Plant Dis. 75:347-353.

Van Loon, L.C. 2007. Plant responses to plant growth-promoting rhizobacteria. European J Plant Pathol.119:243-254. 